\title{
Variations in treatment organisation, practices and outcomes within the Norwegian Opioid Maintenance Treatment Programme
}

\author{
Linn Gjersing ${ }^{1}$, Helge Waal ${ }^{1}$, Jo Røislien ${ }^{1,2}$, Michael Gossop ${ }^{1,3}$ and Thomas Clausen ${ }^{1}$ \\ 1) SERAF - Norwegian Centre for Addiction Research, Institute of Clinical Medicine, University of Oslo, \\ P.O. Box 1039 Blindern, NO-0315 Oslo, Norway \\ 2) Department of Biostatistics, Institute of Basic Medical Sciences, University of Oslo, Oslo, Norway \\ 3) National Addiction Centre, Kings College London, Institute of Psychiatry, United Kingdom \\ Correspondence: Linn Gjersing, SERAF - Norwegian Centre for Addiction Research, Institute of Clinical Medicine, University of Oslo, Oslo \\ E-mail: lgjersing@gmail.com Telephone: +47 22340400
}

\begin{abstract}
Variations within and between opioid maintenance programmes have been identified in other countries such as US and the UK. The aim of this study was to assess possible differences in treatment organisation, practices and outcomes between 14 regional centres within the Norwegian Opioid Maintenance Treatment programme, which were subject to the same government standards. This was a national ecological study conducted in November 2008 in Norway. Marked variations between the centres in caseload, choice of agonists, prescribing doctor, as well as in the use of supervised dispensing and urine drug screening were found. Only prescribed agonist dose was consistent across all centres. Centres in which patients had more illicit drug use had fewer patients with long-term living arrangements, more unemployment, and more patients who reported social security benefits as main income. The differences occurred despite government regulations, policies and guidelines, and frequent national meetings between centre managers. These findings show how government standards may be interpreted and implemented differently.
\end{abstract}

\section{INTRODUCTION}

Opioid maintenance treatment (OMT) is recognised as an effective treatment for opioid dependence and thus plays an important role in national public health policies $(1,2)$. However OMT is not a single uniform type of intervention (1). Treatment may differ with regard to choice of agonist, dose level, length of treatment, as well as intake and discharge criteria (1,3-5). There are also documented differences in take-home privileges and frequency of urine drug screening (1). Some patients receive their doses of methadone or buprenorphine at community pharmacies, while others receive their dose in public or private clinics (6). Treatment objectives may focus differently on harm reduction, rehabilitation or abstinence from all drugs $(1,4,7,8)$. This diversity in treatment is evident between countries, within countries, and even between counsellors within the same treatment programme (9-11).

Diversity in treatment delivery may affect treatment outcomes in various ways. Some OMT programmes prescribe lower methadone doses, and have had higher dropout rates and more illicit drug use compared to programmes that provide high-dose care (>80 mg) (5,12-14). Long-term OMT programmes have had superior treatment outcomes in terms of drug use and individual functioning compared to short-term programmes $(1,3,4)$. Furthermore, treatment programmes with a low caseload are often associated with positive treatment outcomes such as less drug use and higher retention rates $(9,15,16)$. To address these diversities, regulations and guidelines for OMT at state and national levels are commonly used (17-19). They typically apply to treatment issues such as intake and discharge criteria, the GP's role in the provision of OMT, and prescription and dispensing of treatment medications $(17,18,20)$.

The estimated number of injecting drug users is between 8700 and 12300 injecting drug users (predominantly opioids) in Norway (21). The national OMT programme was established in 1998 as part of public health care services (22). Numbers of patients in OMT rapidly increased from 240 patients in the first year to 4542 in 2007 (23). Initially only persons above 25 years with more than 10 years of opioid dependence that had failed abstinence-oriented treatment were accepted into the programme (22). These criteria were subsequently modified; the 25 years age criterion was removed and patients with less than 10 years of opioid dependence were accepted into treatment. Current government guidelines state that the main aims of treatment are that patients should strive for abstinence from all drugs except treatment medication, and as far as possible, be socially rehabilitated (22). Social rehabilitation includes issues such as employment, longterm housing facilities and stable income.

Patients have, until recently, had to establish contact with both social services and a GP to become eligible for treatment. Once an opiate dependent person has been accepted into treatment a GP may act as the prescribing doctor, but treatment should be supervised by a regional OMT centre. Initial acceptance into treat- 
ment and treatment initiation are always the responsibilities of a regional centre.

The programme comprised of, until recently, 14 regional centres that were subject to the same treatment standards specified in government guidelines (22). Managers from all of the centres meet several times a year. The aim of these meetings is to support consistency of treatment between centres. Centres that differ greatly from the other centres in treatment practices or outcomes are identified through annual assessments, and reasons for divergence are discussed. There is no formal regulatory body to ensure that centres follow the same treatment standards. However patients may file individual complaints to the Norwegian Board of Health Supervision. The Board's decisions are applicable to all centres and thus treatment practices in all centres may be changed or modified due to such complaints.

The aim of this study was to assess possible differences in treatment organisation, clinical practices and treatment outcomes between 14 regional centres within the Norwegian OMT programme, which were subject to the same government standards. In addition the study further aimed to investigate possible associations between these factors and drug use and social rehabilitation among patients within the OMT services.

\section{MeTHODS}

\section{Setting}

All the 14 regional OMT centres within the Norwegian OMT programme in 2008 were included. There were 4913 patients in treatment at the end of 2008.

\section{Design}

This study was an ecological study that had a national cross-sectional multicentre design. Data analysis was based upon available aggregated information at centre level provided through the annual assessment of the OMT programme in November 2008. Every year a 53items questionnaire is completed for each OMT patient. Aggregated information on centre level is provided to SERAF - National Centre for Addiction Research which subsequently publishes these data in an annual report.

The questionnaire used in the annual assessments was originally developed in 2001 and taken into use in 2002 (24). The variables within the questionnaire were developed on the basis that this should be the minimum information that the case manager should have of their patients. Information on patients' drug use were mainly from urine drug screening results, however in those cases where such results were not available patients were asked of their current drug use. The patients' case manager either at the OMT centre or at the social service centre completed the questionnaire for each patient, and if possible, the instrument was completed in collaboration with the patient. The questionnaire's inter-rater reliability was assessed in 2004 (24), and items with low reliability $(<0.60)$ were adjusted accordingly.

\section{Treatment organisation and practices}

In this study the measures of treatment organisation included number of patients and staff and caseload. Treatment practices included number of patients prescribed methadone or buprenorphine, median medication dosages, number of patients prescribed their medication either from a GP or the OMT doctor. Additionally the number of patients that were urine drug screened at least once a week and frequency of supervised dispensing were included. Supervised dispensing (observed intake of medication) gives an indication of take-home privileges among patients. OMT centres with high frequency of supervised dispensing would have less take-home doses.

\section{Treatment outcomes}

The measures of treatment outcome were treatment termination rate, number of patients who had used opioids, benzodiazepines, cannabis and central stimulants in the previous four weeks to the annual assessment in November 2008, number of patients with long-term living arrangements (stable accommodation over time), unemployed patients, and patients with social security benefits.

\section{Data analysis}

Aggregated information (number of patients for each variable and total number of patients) for each regional centre (14 centres) was available for analysis. Only valid responses, i.e. completed items, were included in the analysis. Thus the total number of respondents for each item varied from the total number of patients at each centre. Based upon these data it was possible to calculate the prevalence in each centre for each item. Data are presented as median (range) across all centres. The linear regression coefficient (b) and 95\% CI were calculated between all demographic variables and outcome variables.

Some of the outcome variables tended to be correlated. Principal component analysis (PCA) was conducted to assess if it was possible to reduce the number of outcome variables into components. PCA computes linear combinations, i.e. weighted sums, among the variables in question, that explain as much variance as possible. Often the first principal component describes a sufficient amount of the total variation that it provides a good representation of the variables (25).

Descriptive statistics and linear regressions analysis were calculated in SPSS 16.0 (26) and PCA in the open source computer software R (27).

\section{RESUlts}

There were 4913 patients in treatment in the 14 regional OMT centres at the end of 2008. The overall response rate was $81 \%(53-100 \%)$. The median age was 41 (38-44) years, and 30\% (22-37\%) of all patients were women. There were no major differences between OMT centres in age and gender distribution. 
Table 1. Treatment organisation and clinical practices presented as median across all regional OMT centres and prevalence within each centre.

\begin{tabular}{|c|c|c|c|c|c|c|c|c|c|c|c|c|c|c|c|}
\hline OMT centres & Median $^{\mathrm{a}}$ & $\mathrm{A}$ & $\mathrm{B}$ & $\mathrm{C}$ & $\mathrm{D}$ & $\mathrm{E}$ & $\mathrm{F}$ & G & $\mathrm{H}$ & $\mathrm{I}$ & $\mathrm{J}$ & $\mathrm{K}$ & $\mathrm{L}$ & M & $\mathrm{N}$ \\
\hline Response rate & $81 \%$ & $79 \%$ & $53 \%$ & $65 \%$ & $98 \%$ & $82 \%$ & $100 \%$ & $81 \%$ & $95 \%$ & $100 \%$ & $73 \%$ & $73 \%$ & $90 \%$ & $84 \%$ & $55 \%$ \\
\hline No of patients 31.12 .2008 & 296 & 124 & 125 & 167 & 196 & 238 & 280 & 278 & 311 & 324 & 345 & 445 & 417 & 557 & 1106 \\
\hline Patient/staff ratio & 47 & 32 & 26 & 34 & 46 & 33 & 39 & 152 & 47 & 32 & 48 & 231 & 53 & 86 & 83 \\
\hline $\begin{array}{l}\text { Methadone as treatment } \\
\text { medication }\end{array}$ & $61 \%$ & $\begin{array}{l}59 \% \\
(101)\end{array}$ & $\begin{array}{l}66 \% \\
(68)\end{array}$ & $\begin{array}{l}65 \% \\
(109)\end{array}$ & $\begin{array}{l}82 \% \\
(200)\end{array}$ & $\begin{array}{l}61 \% \\
(202)\end{array}$ & $\begin{array}{l}45 \% \\
(299)\end{array}$ & $\begin{array}{l}61 \% \\
(244)\end{array}$ & $\begin{array}{l}49 \% \\
(311)\end{array}$ & $\begin{array}{l}67 \% \\
(353)\end{array}$ & $\begin{array}{l}50 \% \\
(259)\end{array}$ & $\begin{array}{l}70 \% \\
(330)\end{array}$ & $\begin{array}{l}50 \% \\
(428)\end{array}$ & $\begin{array}{l}45 \% \\
(505)\end{array}$ & $\begin{array}{l}73 \% \\
(707)\end{array}$ \\
\hline Buprenorphine dose $^{\mathrm{b}}(\mathrm{mg})$ & 16 & 20 & 16 & 16 & 16 & 16 & 20 & 20 & 16 & 24 & 16 & 16 & 16 & 16 & 18 \\
\hline Methadone dose ${ }^{\mathrm{b}}(\mathrm{mg})$ & 100 & 120 & 90 & 118 & 100 & 100 & 120 & 100 & 100 & 100 & 113 & 100 & 100 & 90 & 110 \\
\hline GP as prescribing doctor & $96 \%$ & $\begin{array}{c}5 \% \\
(101)\end{array}$ & $\begin{array}{l}99 \% \\
(67)\end{array}$ & $\begin{array}{l}97 \% \\
(109)\end{array}$ & $\begin{array}{l}100 \% \\
(203)\end{array}$ & $\begin{array}{l}98 \% \\
(204)\end{array}$ & $\begin{array}{l}99 \% \\
(303)\end{array}$ & $\begin{array}{l}96 \% \\
(245)\end{array}$ & $\begin{array}{l}46 \% \\
(314)\end{array}$ & $\begin{array}{l}100 \% \\
(353)\end{array}$ & $\begin{array}{l}60 \% \\
(259)\end{array}$ & $\begin{array}{l}96 \% \\
(331)\end{array}$ & $\begin{array}{c}3 \% \\
(428)\end{array}$ & $\begin{array}{l}43 \% \\
(496)\end{array}$ & $\begin{array}{l}46 \% \\
(707)\end{array}$ \\
\hline $\begin{array}{l}\text { Number of weekly super- } \\
\text { vised dispensing per patient }\end{array}$ & 3 & 4 & 2 & 2 & 3 & 4 & 3 & 3 & 4 & 3 & 4 & 2 & 3 & 3 & 3 \\
\hline $\begin{array}{l}\text { Drug screened at least } \\
\text { once a week }\end{array}$ & $63 \%$ & $\begin{array}{l}88 \% \\
(98)\end{array}$ & $\begin{array}{l}51 \% \\
(67)\end{array}$ & $\begin{array}{l}43 \% \\
(108) \\
\end{array}$ & $\begin{array}{l}52 \% \\
(201) \\
\end{array}$ & $\begin{array}{l}68 \% \\
(202) \\
\end{array}$ & $\begin{array}{l}78 \% \\
(301) \\
\end{array}$ & $\begin{array}{l}71 \% \\
(238) \\
\end{array}$ & $\begin{array}{l}53 \% \\
(309) \\
\end{array}$ & $\begin{array}{l}56 \% \\
(353) \\
\end{array}$ & $\begin{array}{l}71 \% \\
(254) \\
\end{array}$ & $\begin{array}{l}58 \% \\
(323)\end{array}$ & $\begin{array}{l}90 \% \\
(427) \\
\end{array}$ & $\begin{array}{l}81 \% \\
(498) \\
\end{array}$ & $\begin{array}{l}55 \% \\
(647)\end{array}$ \\
\hline
\end{tabular}

Total $n$ for each item in brackets ${ }^{\mathrm{a}}$ Median across all centres ${ }^{\mathrm{b}}$ Median

\section{Treatment characteristics and practices}

Both number of patients and caseload differed between centres. Number of patients per centre varied from 124 to 1106 , and caseload varied from 26 to 231 (Table 1). The involvement of a GP as the prescribing doctor varied from $3 \%$ to $100 \%$. This means that in some centres the GP was the prescribing doctor to all patients, whereas in other centres OMT doctors provided prescriptions to nearly all patients. Also, prescribing practices varied between centres. In some centres the majority of patients were prescribed methadone and in other centres the majority was prescribed buprenorphine. Five centres prescribed methadone to less than $50 \%$ of their patients, while three centres prescribed methadone to more than $70 \%$ of their patients. All centres prescribed high-dose treatment, regardless of choice of agonist. The median methadone dose was $100 \mathrm{mg}$ (90$120 \mathrm{mg}$ ) and buprenorphine dose was $16 \mathrm{mg}$ (16-24 mg) (Table 1).

The use of supervised dispensing and urine drug screening varied greatly between centres. Three centres supervised dispensing on average twice a week (median), whereas four centres supervised dispensing four times a week (median). Twice as many patients were urine drug screened at least once a week in the centre with the highest proportion of patients drug screened $(90 \%)$ compared to the centre with the least (43\%) (Table 1).

\section{Treatment outcomes}

There were marked variations between centres in illicit drug use among the OMT patients and benzodiazepines were the most commonly used drug (Table 2). In the centre with least use, $16 \%$ had used benzodiazepines previous four weeks compared to $63 \%$ in the centre with most use. Cannabis was the second most commonly used drug among the patients. Of all patients 35\% (median) had used cannabis during the previous four weeks; this varied from $12 \%$ to $49 \%$ between the centres. There were also variations between centres in the use of central stimulants (range 8-24\%) and opioids (range 3-24\%).

There were differences in social rehabilitation between the centres (Table 2). On average $84 \%$ (median) of all patients within the OMT programme had longterm living arrangements. Yet there was a $28 \%$ difference between the centres with least and most patients with such arrangements. There were also large variations in unemployed patients and patients with social security benefits as main income. Unemployed patients ranged from $54 \%$ to $86 \%$, while patients with social security benefits as main income ranged from $3 \%$ to $31 \%$ between the centres.

The median treatment termination rate across all centres was as low as $4 \%$, but it ranged from $1 \%$ to $18 \%$.

\section{Associations between outcome variables}

Centres with high rates of benzodiazepine use, also had high rates of cannabis use $(r=0.90, b=1.00,95 \% \mathrm{CI}$ $0.69,1.31)$ and central stimulants use $(\mathrm{r}=0.61, \mathrm{~b}=1.40$, $95 \%$ CI $0.27,2.54)$. There was no statistically significant association between level of opioid use in a centre and level of other drug use; benzodiazepines $(\mathrm{r}=0.18$, $\mathrm{b}=0.09,95 \%$ CI $-0.22,0.41)$, central stimulants $(\mathrm{r}=0.23$, $\mathrm{b}=0.27,95 \%$ CI $-0.44,0.98)$ and cannabis $(r=0.28$, $\mathrm{b}=0.16,95 \%$ CI $-0.19,0.50$ ).

Centres with high rates of patients with long-term living arrangements, had fewer unemployed patients $(\mathrm{r}=0.55, \mathrm{~b}=-0.43,95 \% \mathrm{CI}-0.84,-0.02)$ and fewer patients with social security benefits as main income $(r=0.66, b=-0.59,95 \%$ CI $-1.01,-0.16)$.

\section{Drug use and social rehabilitation components}

Benzodiazepines, cannabis, and central stimulants use were combined into a single "non-opioid drug use" component using principal components analysis. This component explained $80 \%$ of the variation. The component loadings were almost identical for each of the three variables, implying them being equally important in explaining observed variation. Opioid use was less 
Table 2. Treatment outcomes presented as median across all regional OMT centres and prevalence within each centre.

\begin{tabular}{lccccccccccccccc}
\hline OMT centres & Median $^{\mathrm{a}}$ & $\mathrm{A}$ & $\mathrm{B}$ & $\mathrm{C}$ & $\mathrm{D}$ & $\mathrm{E}$ & $\mathrm{F}$ & $\mathrm{G}$ & $\mathrm{H}$ & $\mathrm{I}$ & $\mathrm{J}$ & $\mathrm{K}$ & $\mathrm{L}$ & $\mathrm{M}$ & $\mathrm{N}$ \\
\hline Opioid use & $13 \%$ & $3 \%$ & $15 \%$ & $5 \%$ & $13 \%$ & $6 \%$ & $16 \%$ & $16 \%$ & $8 \%$ & $9 \%$ & $8 \%$ & $13 \%$ & $14 \%$ & $17 \%$ & $24 \%$ \\
& & $(86)$ & $(65)$ & $(95)$ & $(189)$ & $(190)$ & $(284)$ & $(230)$ & $(298)$ & $(351)$ & $(217)$ & $(262)$ & $(423)$ & $(490)$ & $(568)$ \\
Benzodiazepine use & $46 \%$ & $40 \%$ & $39 \%$ & $45 \%$ & $42 \%$ & $46 \%$ & $45 \%$ & $49 \%$ & $48 \%$ & $16 \%$ & $63 \%$ & $55 \%$ & $36 \%$ & $53 \%$ & $53 \%$ \\
& & $(85)$ & $(66)$ & $(97)$ & $(194)$ & $(192)$ & $(284)$ & $(233)$ & $(294)$ & $(350)$ & $(218)$ & $(278)$ & $(424)$ & $(487)$ & $(578)$ \\
Cannabis use & $35 \%$ & $36 \%$ & $29 \%$ & $32 \%$ & $27 \%$ & $32 \%$ & $42 \%$ & $34 \%$ & $40 \%$ & $12 \%$ & $45 \%$ & $45 \%$ & $23 \%$ & $40 \%$ & $49 \%$ \\
& & $(86)$ & $(65)$ & $(96)$ & $(194)$ & $(191)$ & $(284)$ & $(232)$ & $(293)$ & $(350)$ & $(219)$ & $(267)$ & $(424)$ & $(484)$ & $(562)$ \\
Central stimulant & \multirow{2}{*}{$17 \%$} & $8 \%$ & $13 \%$ & $13 \%$ & $11 \%$ & $18 \%$ & $19 \%$ & $13 \%$ & $24 \%$ & $9 \%$ & $21 \%$ & $17 \%$ & $17 \%$ & $23 \%$ & $18 \%$ \\
drug use & & $(83)$ & $(63)$ & $(96)$ & $(193)$ & $(188)$ & $(282)$ & $(231)$ & $(294)$ & $(350)$ & $(211)$ & $(268)$ & $(424)$ & $(484)$ & $(547)$ \\
Long-term living & \multirow{2}{*}{$8 \%$} & $78 \%$ & $91 \%$ & $86 \%$ & $87 \%$ & $89 \%$ & $83 \%$ & $82 \%$ & $84 \%$ & $88 \%$ & $82 \%$ & $84 \%$ & $92 \%$ & $84 \%$ & $64 \%$ \\
arrangements & & $(101)$ & $(67)$ & $(109)$ & $(199)$ & $(204)$ & $(303)$ & $(244)$ & $(314)$ & $(353)$ & $(259)$ & $(332)$ & $(426)$ & $(486)$ & $(706)$ \\
Unemployed & $77 \%$ & $80 \%$ & $75 \%$ & $86 \%$ & $67 \%$ & $75 \%$ & $73 \%$ & $79 \%$ & $76 \%$ & $54 \%$ & $86 \%$ & $79 \%$ & $69 \%$ & $78 \%$ & $86 \%$ \\
& & $(101)$ & $(67)$ & $(102)$ & $(199)$ & $(202)$ & $(295)$ & $(242)$ & $(314)$ & $(351)$ & $(260)$ & $(327)$ & $(426)$ & $(505)$ & $(710)$ \\
Social security bene- & $10 \%$ & $3 \%$ & $7 \%$ & $7 \%$ & $9 \%$ & $8 \%$ & $7 \%$ & $10 \%$ & $11 \%$ & $7 \%$ & $24 \%$ & $17 \%$ & $11 \%$ & $17 \%$ & $31 \%$ \\
fits as main income & & $(100)$ & $(68)$ & $(103)$ & $(201)$ & $(202)$ & $(290)$ & $(245)$ & $(312)$ & $(352)$ & $(257)$ & $(332)$ & $(425)$ & $(499)$ & $(713)$ \\
$\begin{array}{l}\text { Treatment termina- } \\
\text { tion rate }\end{array}$ & $4 \%$ & $4 \%$ & $2 \%$ & $1 \%$ & $2 \%$ & $4 \%$ & $2 \%$ & $8 \%$ & $5 \%$ & $10 \%$ & $4 \%$ & $3 \%$ & $12 \%$ & $3 \%$ & $18 \%$ \\
\hline
\end{tabular}

Total $n$ for each item in brackets ${ }^{a}$ Median across all centres

associated with the other three drug use variables; benzodiazepines, cannabis and central stimulants.

Due to the association between the variables longterm living arrangements, unemployment and social security benefits as main income, it was possible to combine these variables into a single "social rehabilitation" component using principal component analysis. This component explained $71 \%$ of the variation and the loadings for each of the three variables were almost identical. Results of the linear regression analysis indicated that centres with a high score on the "nonopioid drug use" component (i.e. high use of benzodiazepines, cannabis and central stimulants) had less social rehabilitation among their patients $(\mathrm{r}=0.74$, $\mathrm{b}=0.74,95 \%$ CI $0.31,1.16)$. In comparison there was no association between level of opioid use in a centre and level of social rehabilitation $(\mathrm{r}=0.42, \mathrm{~b}=0.02,95 \%$ CI -0.01, 0.06).

The treatment termination rate was not associated with either of the other outcome variables (opioid use, "non-opioid drug use" component or "social rehabilitation" component).

\section{Associations between treatment characteristics and treatment outcomes}

Linear regression analyses were performed for each of the dependent variables; opioid use, "non-opioid drug use" component, "social rehabilitation" component, and treatment termination rate. None of the proposed explanatory variables (number of patients and staff, caseload, type of agonist, medication dose, prescribing doctor, supervised dispensing, urine drug screening) were associated with any of the dependent variables.

\section{DISCUSSION}

Marked differences were found in treatment organisation, practices and patient outcomes within the Nor- wegian OMT programme. Variations were found in caseload, choice of agonists, prescribing doctor, as well as in the use of supervised dispensing and urine drug screening. Only prescribed methadone and buprenorphine dose was consistent across the regional centres. Centres with high rates of benzodiazepine use had more cannabis and central stimulants use. Also, centres with more drug use tended to have less satisfactory social rehabilitation among their patients in terms of long-term living arrangements, unemployment, and social security benefits as main income.

Diversity in treatment organisation, practices and outcomes is common both between and within countries $(1,8,14,28,29)$. Yet this study was conducted within a national OMT programme, comparing 14 regional centres that were subject to the same government treatment standards, and not between independent treatment programmes. The data show that centres organised treatment differently, and, more importantly, that patients did not have similar outcomes. This suggests that several treatment practices existed within the one national programme and that the regional centres performed differently.

Differences in treatment practices would not be of concern if all centres had outcomes in line with programme aims. The main programme aims were reduced drug use and improved social rehabilitation (long-term living arrangements, employment and other income than social security benefits as main income). However there were differences between centres in patient drug use and level of social rehabilitation. Also, patients are not entirely free to choose their treatment centre due to treatment organisation. Treatment relies on long-term three-party collaboration between an OMT centre, a GP and social services, thus transfers are difficult due to logistical and geographical challenges. This means that patients are required to accept their local centre's treatment standards and practices. 
One reason for variations in drug use and social rehabilitation among patients could be differences in patient population. Data from 2006 and 2007 were analysed and the same differences between centres were found. As in 2008, there was no difference between centres in patients' age and gender distribution. There may be other patients' characteristics than age and gender distribution that explain some of the variations between regional centres, but such data were not available for analyses. However based upon the differences in treatment practices between centres documented in this study, it is likely that some of these differences were due to variations in quality of treatment provided.

OMT is a contentious issue in terms of treatment aims and organisation $(20,30)$. Differences between policy and professional practices are recognised by many public health professionals (31). Such differences would be assumed to be even greater in contentious fields such as OMT. This means that there will always be discussions around OMT regulations, policies and practices which are likely to diverge $(17,32)$. A possible reason why treatment organisation and practices differed may have been that current treatment guidelines conflicted with what staff interpreted as evidencebased. Another reason could be that there were not enough resources to adhere to the government treatment standards at least in some centres. A third reason could be the lack of a regulatory body that ensured adherence to a minimum of treatment standards. It is also possible that treatment standards specified by the government were too open to interpretation. But whatever may have been the underlying reasons, this study shows that government treatment guidelines and frequent contact between centre managers did not prevent the development of treatment variations.

This study was an ecological study, which included data from all regional OMT centres representing all Norwegian OMT patients. The ecological design does not permit inference as to causality, but it was possible to describe what differences existed within the national programme. It is also likely that other factors than those available for analyses have influenced patients drug use and level of social rehabilitation such as employment. Nonetheless, this study gives a nationwide picture of an OMT programme.

\section{Conclusions}

It is of concern, both to individual patients and policy makers that the regional OMT centres did not have more similar treatment organisation, practices and outcomes. The differences exist despite government regulations, policies and guidelines and frequent national meetings between all the centre managers. This illustrates some of the challenges that are encountered in the provision of a large nationwide treatment programme. It also exemplifies how government standards may be interpreted and implemented differently between treatment centres and shows that implementation of such standards may be difficult. Policy makers and stakeholders need to be aware of and address variations in treatment practices which may develop within large national treatment programmes, particularly if they result in different treatment outcomes.

\section{REFERENCES}

1. Ball JC, Ross A. The effectivness of methadone maintenance treatment. New York: Springer, 1991.

2. Clausen T, Anchersen K, Waal H. Mortality prior to, during and after opioid maintenance treatment (OMT): a national prospective cross-registry study. Drug Alcohol Depend 2008; 94 (1-3): 151-7.

3. Stewart D, Gossop M, Marsden J. Methadone treatment: outcomes and variation in treatment response within NTORS. In: Strang J, Tober G, eds. Methadone matters evolving community methadone treatment of opiate addiction. London: Martin Dunitz, 2003: 249-91.

4. Caplehorn JR. A comparison of abstinence-oriented and indefinite methadone maintenance treatment. Int $J$ Addict 1994; 29 (11): 1361-75.

5. Pollack HA, D'Aunno T. Dosage patterns in methadone treatment: results from a national survey, 1988-2005. Health Serv Res 2008; 43 (6): 2143-63.

6. Winstock AR, Lea T, Sheridan J. Prevalence of diversion and injection of methadone and buprenorphine among clients receiving opioid treatment at community pharmacies in New South Wales, Australia. Int $J$ Drug Policy 2008; 19 (6): 450-8.

7. Dole VP, Nyswander ME. Rehabilitation of heroin addicts after blockade with methadone. $N$ Y State J Med 1966; 66 (15): 2011-7.

8. Gossop M, Stewart D, Marsden J. Treatment process components and heroin use outcome among methadone patients. Drug Alcohol Depend 2003; 71 (1): 93-102.

9. D'Aunno T. The role of organization and management in substance abuse treatment: Review and roadmap. $J$ Subst Abuse Treat 2006; 31 (3): 221-33.

10. Gossop M, Grant M. Six country survey of the content and structure of heroin treatment programmes using methadone. Br J Addict 1991; 86 (9): 1151-60. 
11. Stewart D, Gossop M, Marsden J, Strang J. Variation between and within drug treatment modalities: data from the National Treatment Outcome Research Study (UK). Eur Addict Res 2000; 6 (3): 106-14.

12. Strain EC, Bigelow GE, Liebson IA, Stitzer ML. Moderate- vs high-dose methadone in the treatment of opioid dependence: A randomized trial. JAMA 1999; 281 (11): 1000-5.

13. Peles E, Schreiber S, Adelson M. Factors predicting retention in treatment: 10-year experience of a methadone maintenance treatment (MMT) clinic in Israel. Drug Alcohol Depend 2006; 82 (3): 211-7.

14. Liu E, Liang T, Shen L, Zhong H, Wang B, Wu Z, et al. Correlates of methadone client retention: A prospective cohort study in Guizhou province, China. Int J Drug Policy 2009; 20 (4): 304-8.

15. Woodward AM, Raskin IE, Blacklow B. A profile of the substance abuse treatment industry: organization, costs, and treatment completion. Substance Use Misuse 2008; 43 (5): 647-79.

16. Broome KM, Flynn PM, Knight DK, Simpson DD. Program structure, staff perceptions, and client engagement in treatment. J Subst Abuse Treat 2007; 33 (2): 149-58.

17. Jaffe JH, O'Keeffe C. From morphine clinics to buprenorphine: Regulating opioid agonist treatment of addiction in the United States. Drug Alcohol Depend 2003; 70 (2 Suppl): S3-S11.

18. Rettig RA, Yarmolinsky A. Federal regulation of methadone treatment. Washington DC: National Academy Press, 1995.

19. Kleber HD. Methadone maintenance 4 decades later: thousands of lives saved but still controversial. JAMA 2008; 300 (19): 2303-5.

20. Joseph H, Stancliff S, Langrod J. Methadone maintenance treatment (MMT): a review of historical and clinical issues. Mt Sinai J Med 2000; 67 (5-6): 347-64.

21. EMCDDA. The drug situation in Norway. Lisbon: European monitoring centre for drug and drug addiction (EMCDDA), 2010.

22. Waal H. Merits and problems in high-threshold methadone maintenance treatment. Evaluation of medicationassisted rehabilitation in Norway 1998-2004. Eur Addict Res 2007; 13 (2): 66-73.

23. Waal H, Clausen T, Håseth A, Lillevold PH. The 2007 annual assessment of the Norwegian OMT programme. Oslo: Seraf - Norwegian Centre for Addiction Research, University of Oslo, 2008, Report No 1.

24. Vånar M. Reliability testing of the questionnaire used in the annual OMT assessments. Oslo: Seraf - Norwegian Centre for Addiction Research, University of Oslo, 2005, Report No 1.

25. Preacher KJ, MacCallum RC. Repairing Tom Swift's electric factor analysis machine. Understanding Statistics 2003; 2 (1): 13-43.

26. SPSS Inc. SPSS release 16.0 statistical software [computer program]. Chicago, SPSS Inc., 2008.

27. R Development core team. R: a language and environment for statistical computing [computer program]. Vienna: R Foundation for statistical computing. 2008.

28. Ball JC, Corty E, Petroski SP, Bond H, Tommasello A, Graff H. Medical services provided to 2,394 patients at methadone programs in three states. J Subst Abuse Treat 1986; 3 (3): 203-9.

29. Ball JC, Lange WR, Myers CP, Friedman SR. Reducing the risk of AIDS through methadone maintenance treatment. J Health Soc Behav 1988; 29 (3): 214-26.

30. Payte JT. A brief history of methadone in the treatment of opioid dependence: a personal perspective. $J$ Psychoactive Drugs 1991; 23 (2): 103-7.

31. Wehrens R, Bekker M, Bal R. The construction of evidence-based local health policy through partnerships: Research infrastructure, process, and context in the Rotterdam 'Healthy in the City' programme. J Public Health Policy 2010; 31 (4): 447-60.

32. Irwin KS, Fry CL. Strengthening drug policy and practice through ethics engagement: an old challenge for a new harm reduction. Int J Drug Policy 2007; 18 (2): 75-83. 